DESIGN AND DEVELOPMENT OF CRYOSTABLE SUPERCONDUCTING

OHMIIC IEEATING COILS FOR A TOKARLAK

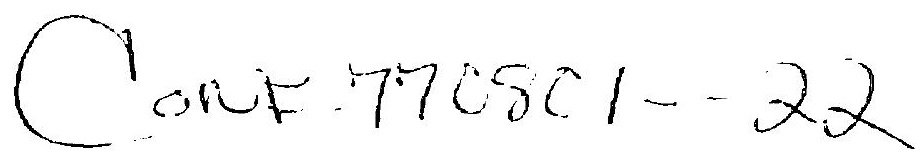

S. T. Wang, S. H. Kim, L. R. Turner, K. M. Thompson,

W. F. Praeg, C. I. Krieger and R. L. Kustom

Prepared for

International Cryogenics Materials Conference

Boulder, $\mathrm{CO}$

August 2-5, 1977

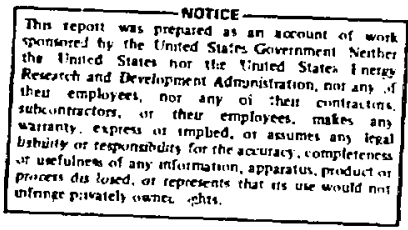




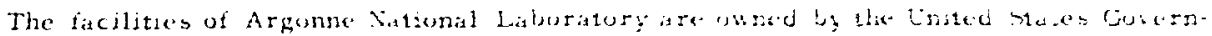

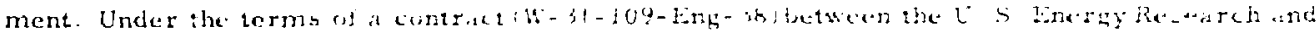

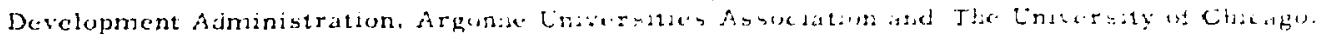

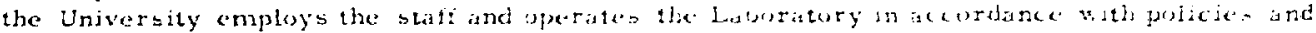

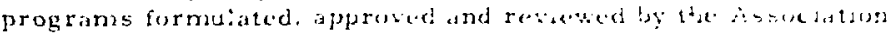

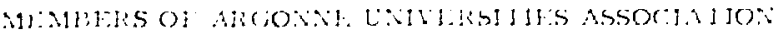

The Unuversity of Arizuma

Carmegu-Mallon Latacersty Cass Western Reserue Libuersily

The Unularsily of Chaciges

Unuersity of Conesmat:

Illinois Institute of Techosedery

Unuersity of limmons

Indiania Unuerers?

Iowa State Universty

The limuresty os lowit

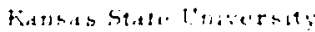

The lonstronds, et Fiansed

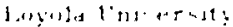

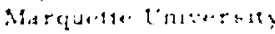

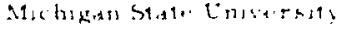

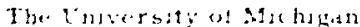

Linuersity os sintsenogd

Univetsily ef Missind

Nerthoustert Undersity

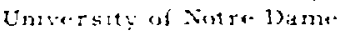

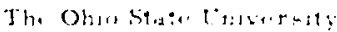

Ohan lawertett?

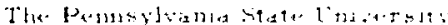

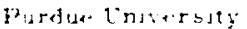

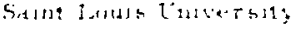

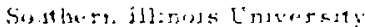

The University of lexat al Auth

Washington briversty

Wayne State Universily

The Linicersity ut thocussin

\section{NOTICE}

Thas report wis propalyed as an aceount of work spunsored is) the United States Government. Neither the linted Stites nux thr United States Energy liesearch and Deselapment Arministation. nur any of thear cmplojeces ner any of thes contractors, sutcontractors, or thes: employers makes any warranty, copress or implied. or assumes any legal latbil ity or responsibility for the accuracy completences ar ubefulncss of any information, apparatus, product or process disclosed, or represents that its use wisuld not infringe privately-owned rights. Mention of commercial products. their manufacturess. or their suppliers in this pubijation does not imply or connote approval or disappruval of the product by Argonne Xational Laboratory or the U. S. Energy Research and Development Adminjstration 


\title{
DESIGN AND DEVELOPMENT OF CRYOSTABLE SLPERCONDUCTING OHMIC HEATING COILS FOR A TOKAMAK*
}

\author{
S. T. Wang, S. H. Kin, L. R. Turner, K. M. Thompson, \\ W. F. Praeg, C. I, Krieger and R. L. Kustom \\ Argonne National Laboratory \\ Argonne, Illino is 60439
}

\section{INTRODUCTION}

A conceptual design on the superconducting ohmic heating (OH) coil has been made for the GA/ANL TNS Tokamak Reactor studics. The primary advantage of a superconducting oH coil is the minimization of equipment and operaticnal costs. This is primarily a result of the much reduced power supply and energy storage costs. Three hundred $\mathrm{M}$ peak power and $11 \mathrm{MW}$ rms power would be required to drive a room temperature copper Oll coil system, as opposed to $16 \mathrm{MN}$ and $4 \mathrm{M}$, respectively, for a superconducting oll coil. Another reason is that, to reuuce the overall TNS tokamak cost, the flux core of OH coils should be small. However, a much better utilization of the flux core can be achieved with superconducting on coils by placing the support cylinder of superconducting coroidal field (TF) coils within the inner diancter of the superconducting Oll coils, thus ailowing the outer diameter of the OH coils to be in close contact with TF coils. Recent scoping studies indicate that superconducting on coils will cost only half as much as room temperature copper OA coils ( $\$ 15$ M ver: . $\$ 30 M)^{(1)}$.

The second feature of the superconducting 0 il coil design is the parallel coil connection. This is very important because it confers several imporiant 
advantages upon the system: (1) in order that the equilibriun field .EF) coils are magnecically decoupled from the oH coil, the OH coil system is required to be connected in parallel with the EF coil and the number of turns of each $\mathrm{OH}$ coil and EF coil must be equal. Under these conditions, since each OH coil and EF coil experiences the same flux change, the induced EF coil current is zero in the absence of a plasma current. Consequently, dividing the $\mathrm{OH}$ coil into many parallel paths means that the number of turns in each $\mathrm{OH}$ coil and EF coil can be greatly reduced. Thus, both the EF coil and Odi coil systen will require lower voltage and reasonable currents in the coils; (2) superconducting oH coils with multiple parallel-connected paths will inherently adjust their respective currents to mininize the flux leakage within the TF coil envelope. This is because all parallel paths of oH coils see the same volt-seconds (V-s) and therefore must all experience the same interior flux variations.

In the development aspect, the results of basic cable development and tests will be described. The design and construction of a prototype 1.5 MJ cryostable pulsed coil and its nonnetallic cryostat will be presented.

\section{DESIGN DESCRIPTION}

Design Requirement and Rationale

The design requirements for the V-s are specified as a result of trade-off studies-for plasma ignition and heating and studies of burn cycle dynamics. The size, stored energy, field levels and $\mathrm{dB} / \mathrm{dt}$ of the of coil are directly related to the V-s requirements. The reference design requires a total of 
$37 \mathrm{~V}-\mathrm{s}$ in a complete cycle of ignition, heating and burning. The reference design has a mean flux core radius of $0.86 \mathrm{~m}$ with a $1.0 \mathrm{~m}$ outer radius and a $0.7 \mathrm{~m}$ inner radius. A symmetrical bipolar flux change of $37 \mathrm{~V}-\mathrm{s}$ is achieved with an $8 \mathrm{~T}$ central field. The maximum $\mathrm{dB} / \mathrm{dt}$ is $8 \mathrm{~T} / \mathrm{s}$ with a $1 \mathrm{~s}$ ramp $t$ ime.

The choice of $8 \mathrm{~T}$ for the central field and $8 \mathrm{~T} / \mathrm{s}$ for the rate of change of flux is based on a study of the rational limits on the central field and the $\mathrm{dB} / \mathrm{dt}{ }^{(2)}$. It can be seen that, for a given $V-s$ requirement, the sinaller the flux core, the higher the central field and the $\mathrm{dB} / \mathrm{dt}$ would be. On the other hand, higher fields and higher $\dot{B}$ require more superconductor vclume, more stabilizer copper volume, more stinless stcel for support and larger heliun channel volume. Therefore, there exists a minimum of oll coil radius wich also minimizes the overall. cost of the entire reactor. Although the anaiyses werc based on reasonable size of filaments, twisting pitches and strand diameters in the cable, good engineering intuition is uscd in selecting these parameters.

\section{Coil Configurations}

The coil configurations established for the suparconducting of coil is schematically shown in Figure 1. The coil system consists of a central solenoid, coils 9 through 30, field profilc coils, coils 3 through 8 , and two trim coils, coils 1 and 2 .

The central silenoid contributes essentially the central field. The field protile coils, positioned approximately on the $f 1$ ux line and so spaced that they do not interfere with reactor penetrations, are primarily used to correct the superimposing fields in the TF cuil and in the plasma regions. The two trim coils are needcd to eliminate the stray ficlds in the plasma Iegion due to the leakage of flux between the field profile coils and the other stray 
fields, either due to misalignments of TF coils or due to the eddy currents of the first wall, etc. Trim coil number $\%$ is used to primarily correct the axial field component and trin coil number ?, the radial field component.

The central solenojd is broken into 22 parallel electrical paths of 20 turns each. The field profile coils of 20 turns each, are connected in parallel with the central solenoid soils. The two trim coils, however, are excited independently by a small power supfly. Adjustments of both coils will permit minimization of the chamber fiedd prior to plasma siartup. The magnet characteristics of the superconducting $\mathrm{OH}$ coil are listed in Table $\mathrm{I}$.

Coil structure, Cryostat and Cursent Leads

The proposed TF coil support cylinder is a fiberglass reinforced plastic such as G-10 or G-11. The cylinder is positioned inside the of coil with axial support rings transmitting the load between the support cylinder and the TF coil. The plastic rings of $5 \mathrm{~cm}$ thickness are axially compressed to $30 \mathrm{kpsi}$. These rings could be solid or hollow discs depending upon the outcome of cost and stress anaiyses. For a 6000 psi centering pressure rrom the TF coils (at $10 \mathrm{~T}$ ), the axial thickness for each of the coils in the central solenoid is $20 \mathrm{~cm}$. It is proposed that liquid helium be penecrated to the bottom of coils and the gas be vented at the top. It is tentatively decided that two concentric arrays of holes of about $3 \mathrm{~cm}$ diameter each, will be made in each of the supporting plastic rings as illustrated in Figure 1. The separation of the liquid s .ply from the gas venting is important to assure the success of a fast pulsed oH coil in a pool boiling system. 
The current leads with a total of about 60 pairs are arranged in concentac circles at the top. This arrangement will minimize the stray fields due to tije leads. The arrangements will also simplify the support of current leads because a clamping ring inserted between the leads will neutralize the external forces. The refrigeration. requirements for the 60 pairs of $80 \mathrm{ks}$ leads could be significantly reduced if the leads were designed for the rms current of about $25 \mathrm{kA} \mathrm{A}$ instead of $80 \mathrm{kA}$ because the on cycle is $30 \mathrm{~s}$ in a total cycle time of about $300 \mathrm{~s}$. $\mathrm{Nb}_{3} \mathrm{Sn}$ stabilized with sufficient copper will also reduce the refrigeration cost of leads because the refrigerated cold gas could be introdiced at about $15 \mathrm{~K}$ rather than $4.2 \mathrm{~K}$.

The helium vessels will be plastic G-10. The outer wall will bz about 5 $\mathrm{cm}$ thick. This is sufficient for a 500 volt coil voltage. The inner wall will be thick enough to prevent buckling. The cryostats for the remaining bundle coils will have circular cross-sections, and will be supported by the reactor structure.

$80 \mathrm{kA}$ Cable Design and ac Losses

The $80 \mathrm{kA}$ cable design, as illustrated in Figure 2, was based on the results of an on-going Argonne National Laboratory pulsed-coil program as described in the following sections. The requirements of low loss and cryostability are conflicting requirements. A compromise between the two must be made when selecting a cable design. The basic principle chosen is to achieve cryortability within basic cables. The final cable may consist of many basic cables stranded with full transposition. To limit eddy current loss, only limited current sharing among basic cables is ailowed. These principles are incorporated in the $80 \mathrm{kA}$ 
cable design. The ac losses are the filament loss. the eddy current loss within the cryostable basic cable, and the eddy current loss in the structural member of the cable. These losses are 1 isted in Table I.

\section{Parallel Operations and Stability}

Considerable effort has been spent in developing codes to determine the currents for multiple farallel paths. The codes consist of the computations of self and mutual inductance of all parallel paths and computations of currents in each parallel path by solving a set of simultaneous equations for the parallel-connected loop currents. The coil currents in the parallelconnected coils are tabulated in Table I. These currents give a mignimu stray field in the piasma and the TF coil regions as shown in Figure 1.

The effects due to change in coil locations have been calculated. The effects of some coils going normal were also investigated. These effects will be reported elsewhere ${ }^{(3)}$.

\section{DEVELOPMENT OF CRYOSTABLE PULSED COILS}

\section{Basic Cable Studies}

Figure 3 illustrates three basic cables chosen. As stated previously, the basic principle chosen is to achieve cryostability within the basic cables. It was originally hoped that mechanical contact through stranding processes may provide enough electrical contact for current sharing while simultaneously fulfilling the requirement of low ac loss. To provide a cushion-like contact, each strand, superconducting composite or pure OFHC wire is tinned with staybite. 
Table I. Magnet Characteristics of TNS Superconducting Ohmic lleating Coil

Central Field (I)

Maximum dB/dt ( $T / s)$

Total Ampere-Turns $(\Lambda-T)$

Total Anpere-Metcrs $(A-M)$

Source current $(A)$

Source voltage (V)

Total Inductance $(\mu \mathrm{H})$

Stored Energy

AC Losses per Cycle (estimations)

Filament Loss $(J)$

Conductor Eddy Current Loss ( $J$ )

Central Solenoid (coils $\rightarrow$ through 30)

$\begin{array}{ll}\text { I.D. } & 1.4 \mathrm{~m} \\ \text { O.D. } & 2.0 \mathrm{~m} \\ \text { Height } & 11.0 \mathrm{~m} \\ \text { Current } & (81 \pm 7.6) \mathrm{kA}\end{array}$

8

8

$82 \times 10^{6}$

$490 \times 10^{6}$

$4.1 \times 10^{6}$

360

85.1

$715 \mathrm{MJ}$

$694.241 . J$

$\div 20,000$

574,241

Field Profile Coils

\begin{tabular}{cccc} 
Coil No. & $\underline{\mathrm{R}(\mathrm{m})}$ & $\underline{Z(\mathrm{~m})}$ & $\underline{I(\mathrm{k})}$ \\
\hline 3 & 9.12 & 6.12 & 3.96 \\
4 & 7.12 & 7.12 & 6.54 \\
5 & 3.62 & 7.12 & 19.76 \\
6 & 1.47 & 6.55 & 80.12 \\
7 & 1.31 & 6.14 & 53.85 \\
8 & 1.07 & 5.72 & 88.12
\end{tabular}

Trim Coils 
The basic cables have a short sample current of $405 \mathrm{~A}$ at 5 I and a ratio of $\mathrm{Cu} / \mathrm{NbTi}$ of $15: 1$. The cryostability test was made using a 4-foot long sample, noninductively wound. The current sharing characteristics of all three cables indicate that the minimum propagating currint, $\mathbb{I}_{\text {mp. }}$ is slightly greaten tlan the critical current, $I_{c}$, but the recovery current, $I_{r}$, is less than $I_{c^{*}}$ There is little difference in the current sharing characteristics among the three basic cables. Therefore, the stranding contacts apparently did not provide a sufficient margin for current sharing.

About $300 \mathrm{~m}$ lengths were fabricated of each of tince cables. These cables were wound into three test coils with a axial winding length of $14 \mathrm{~cm}$, the coil i.d. is $3.2 \mathrm{~cm}$ and the coil o.d. is $22.2 \mathrm{~cm}$. The inductance is $25.7 \mathrm{mtl}$ and the stored energy is $3000 \mathrm{~J}$. These coils were cycled many times betwcen 0 A and 589 A (critical current at $3.3 \mathrm{~T}$ ) wit a ramping rate of as much as $3.3 \mathrm{~T} / \mathrm{s}$ without going normal. However, if the coils are charged beyond $600 \mathrm{~A}$, sections of conductor in the coils go normal and they recover completely at a current lower than the critical current.

The ac losses of these coils were measured by a gas boil-off calorimeter. A heater was attached at the top of the coil for losses calibration. The ac losses for coils using cable (b) and (c) in Figure 3 are nearly identical and are about $2 \mathrm{~W}$ for a $\dot{\mathrm{B}}$ of $1.65 \mathrm{~T} / \mathrm{s}$ and a central field of $3.3 \mathrm{~T}$. The losses are $4 \mathrm{~W}$ for a dB/dt of $3.3 \mathrm{~T} / \mathrm{s}$ and a central field of $3.3 \mathrm{~T}$. The ac losses for coil using cable (a) was found to have a surprisingly high ac loss of 8 at a $\dot{B}$ of $1.65 \mathrm{~T} / \mathrm{s}$ with a central fi=ld of $3.3 \mathrm{~T}$.

Current sharing characteristics of cable (b) under various conditions are 11lustrated in Figure 4. Since stranding contact coes not provide enough of a 
margin for current shariis' (curve a), the current siaring terminal characteristics for the case where the entire cable is soldczed together rere investirgted. Tise results indicated that both $I_{r}$ and $I_{m p}$ are much greater than $I_{c}$ as shoss. in curve b, ligure 4. However, it is quite obvious that the ac losses of the soldered cable is rather large.

The cable configuration giving the best compromist between stalility ind ac losses is shown in Figure 5a. The six pure copper wires are soldered to the superconducting composite forming an essential current sharing subgroup. A thin coating of glyptal varnish is brushed on the surface of cach of the three subgroups in the basic cable. The high dieluctric strength coating; serves to reduce the eddy current losscs anong the subsroups. The coating is thin enough ( $\sim 0.0125 \mathrm{~mm})$, however, so that 1 imited current slatimg amon: subgroups wijl te allowed. Also, the heal transfer of the soil ing helium will not be affect d because the coating is thin. In fact, the mindatin filu boiling heat transfer rate will be enhanced as a result of the thin coating. The current sharing of the cable was tested and shom in curve $c$, Figure 4. prictional heating of the basic cable was also studied. This and othor results will be reported elsewhere $(4,5)$.

$12 \mathrm{kA}$ Cable Development and Parallel Coil. Operation

Figure 5b illustrates the $12 \mathrm{kA}$ cable design for a $1.5 \mathrm{MJ}$ pulsed coil. To form the $12 \mathrm{kA}$ cable, twenty-four basic cables are twisted around a stainluss steel strip about $0.8 \mathrm{~mm}$ thick by $28.5 \mathrm{~mm}$ wide at a twisting pitch of abcut i14 min. The stainless steel strips, which are well insulated from the basic cables, will serve as the backbone in the cabling process and as the structural member 
to support loop stress of the $1.5 \mathrm{MJ}$ coil. Supercon, Inc., is comissioned to produce a $600 \mathrm{~m}$ long cable by August, 1977. The first 69 m will bc labricated first as a dry run cable. The cable conductor will be wound into two 20-turn pancake coils for parallel operation tests. Each pancake coil shall have 20 turns with a pancake o.d. of $61 \mathrm{~cm}$ and an i.d. of about $36 \mathrm{~cm}$. Feasibility and stability of parallel operations over a wide range of $\dot{B}$ will be fully investigated.

\subsection{MJ Coil Design and Fabrications}

The design of the $1.5 \mathrm{MJ}$ prototype cryostable pulsed coils is completed. Fabrication of a G-10 coil form has started. Coil winding is planned for the end of August, 1977. The magnet characteristics are tabulated in Table $\mathbf{L I}$. The magnet and its plastic dewar are shown in Figure 6 . The 1.5 MJ coil will be cryostable. The ac losses will be large but tolerable. The large eddy current losses were derived froa the fact that the twisting pitch of the superconducting composite is too long for fast pulsed application. These composites are available at ANL and the level of funding did not permit purchase of more suitable superconducting composites. Another important goal of building the 1.5 $\mathrm{MJ}$ coil is to energize and deenergize the magnet over a wide range of $\mathrm{dB} / \mathrm{dI}$ (from $2 \mathrm{~T} / \mathrm{s}$ up to $14 \mathrm{~T} / \mathrm{s}$ ). The power supply for the $1.5 \mathrm{MJ}$ coil is a $7 \mathrm{M}$ power supply wit: $700 \mathrm{~V}$ peak voltage and $11 \mathrm{kA}$ peak current. AC loss measurement by an electrical method is also planned. For this purpose construction of a linear mutual inductor, cooled in liquid nitrogen, is underway.

\section{Development of a Large Plastic Dewa:}

The $1.5 \mathrm{MJ}$ pulsed coil requires rapld charging and discharging; consequent $1 \mathrm{y}$, it is necessary to use nonconducting dewars to minimize eddy current losses. 
Table II. ANL 1.5 MJ Pulsed Superconducting Coils

Central Field

Peak Field

$I_{\max }$

L.

E

Coil I.D

Coil 0.D.

Axial Length

Cable Length

No. of Layers

No. of Turns/Layer

Layer-to-Layer Spacing

Cryostable Recovery Heat Flux

Conductor Current Density

Average Current Density

Exposed Surface

AC Losses $(\dot{B}=2 \mathrm{~T} / \mathrm{s})$

Instantaneous Matrix Eddy Current

Loss

Instantancous Hysteresis Loss

Instantaneous Eddy Current Loss in S.S. Strip
$4.3 \mathrm{~T}$

$12 \mathrm{kA}$

20 null

$1.5 \mathrm{MJ}$

$40.6 \mathrm{~cm}$

$86.4 \mathrm{cra}$

$61 \mathrm{~cm}$

531 田

15

16

$6.35 \mathrm{~mm}$

$0.5 \mathrm{H} / \mathrm{cm}^{2}$

$6446 \mathrm{~A} / \mathrm{cm}^{2}$

$2600 \mathrm{~A} / \mathrm{cm}^{2}$

Approx. $50 \%$

$50 \mathrm{~W}$

$17.2 \mathrm{~W}$

$10 \mathrm{~W}$ 
The plastic cryostat, as shown in Figure 6, will consist of two tanks with 100 layers of superinsulation between. The inner tank will have an i.d. of $91.4 \mathrm{~cm}$ $\mathrm{cm}$ and a depth of $152.4 \mathrm{~cm}$ with internal pressure rating of $30 \mathrm{psig}$. The wall thickness is $0.95 \mathrm{~cm}$. The outer tank has an i.d. of $107 \mathrm{~cm}$, a depth of $156.5 \mathrm{~cm}$ and a wall thickness of $1.27 \mathrm{~cm}$. Two rings are provided to reinforce the tank against buckling. Both tanks are made of fibrrglass reinforced lletron 31 polyester with $35 \%$ glass components. Hasbrouck Plastics, Inc., New York is commissioned to fabricate both tanks in July, 1977. The superinsulation is slit at two places to reduce the eddy current heating. The heat leak of the plastic tank is estimated at $5 \mathrm{~W}$.

\section{ACKNOWLEDGEMJNT}

The authors appreciate the stimulating discussions and suggestions of J. Purcell of General Atomics Company in the design of the TNS superconducting OH coil.

\section{REFERENCES}

1. TNS Scoping Studies, Interim Status Report, ANL/FPP/77-a, Argonne Nationäi Laboratory, Argonne, Illinois or GA-A14412, General Atomic Company, San Diego, California (May, 1977).

2. L. R. Turner, "Limits on the Field and Rate of Change of Field in the Ohmic Heating Solenoid for TNS," to be published as ANL/FPP/TM-32.

3. S. T. Wang, et al., "Design and Development of Cryostable Superconducting Ohmic Heating Coils for a Tokamak," to be published in Sixth International Conference on Magnet Technology.

4. S. T. Wang, S. H. Kim, W. Praeg and C. Krieger, "ANL Pulsed Coil Program: Present Results and On-going Program", to be published as ANL/FPP Technical Memorandum. 
5. R. L。 Kustom and S. T. Wang, "The ANL Researcn and Develonment Program for Large Pulsed Superconducting Coils and Energy Storage and Transfer for Tokamak Fusion Reactors," Argonne National Laboratory, Ar énne, Illino is (June, 1977). 
FIGURE CAPTIONS

Figure 1 Schematics of TNS superconducting ohmic heating system.

Figure $2 \quad 80 \mathrm{kA}$ cable design.

Figure 3 Three cryostatic stable basic cables superconducting wire (SC): 40 mils dia., 2041 filaments, filament diameter $5 \mu, c u / s c=1.8$ and twisting pitch $1.27 \mathrm{~cm}(=2 \mathrm{TPI})$. (a) three sc wires are twisted at 4 TPI and six cu wires are twisted around the sc at 1.5 TPI, (b) and (c): six cu wires and one sc wire are twisted at 2 TPI and those three subgroups are twisted at $1.5 \mathrm{TP}^{\mathrm{I}}$.

Figure 4 Current sharing characteristics of cable (b) of Figure 3 . (a) bare wires and stranding contact, (b) completely soldered and (c) subgroups ere soldered and insulated.

Figure 5 (a) selected basic cable, (b) 12 kA cryostable cable. Figure 6 Fiberglass reinforced plasic dewar and $1.5 \mathrm{MJ}$ coil. 


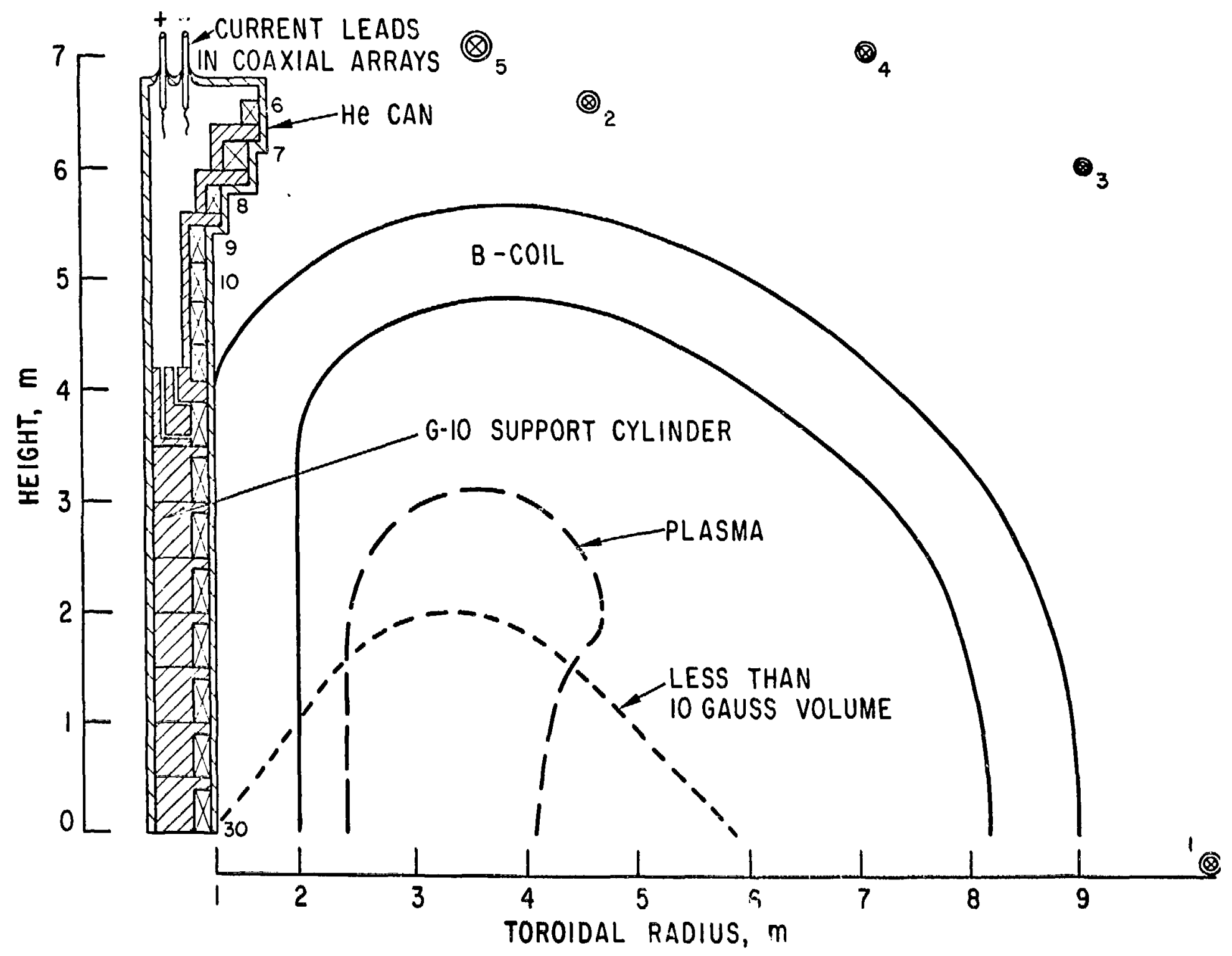


1000A BASIC CABLE

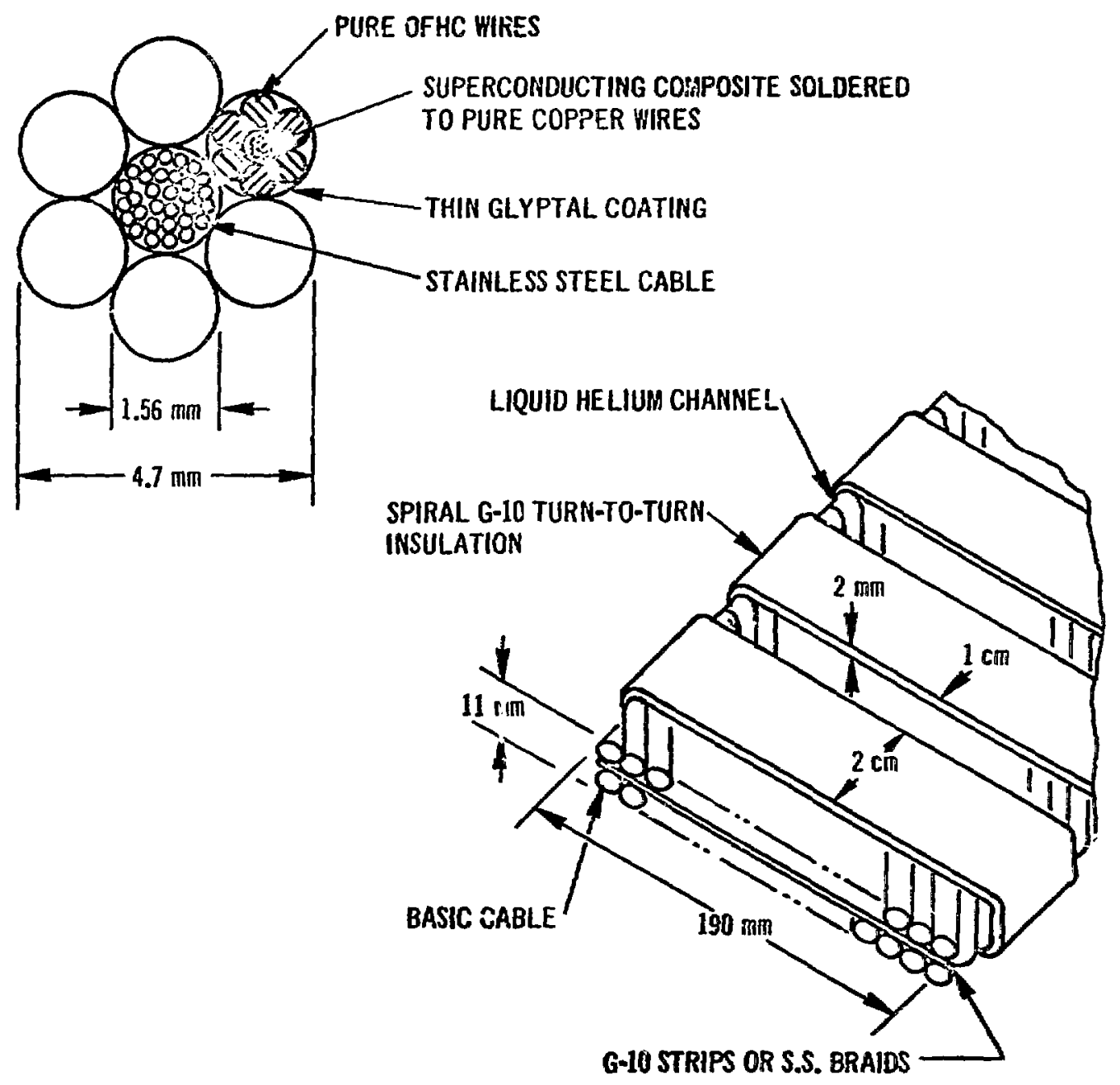




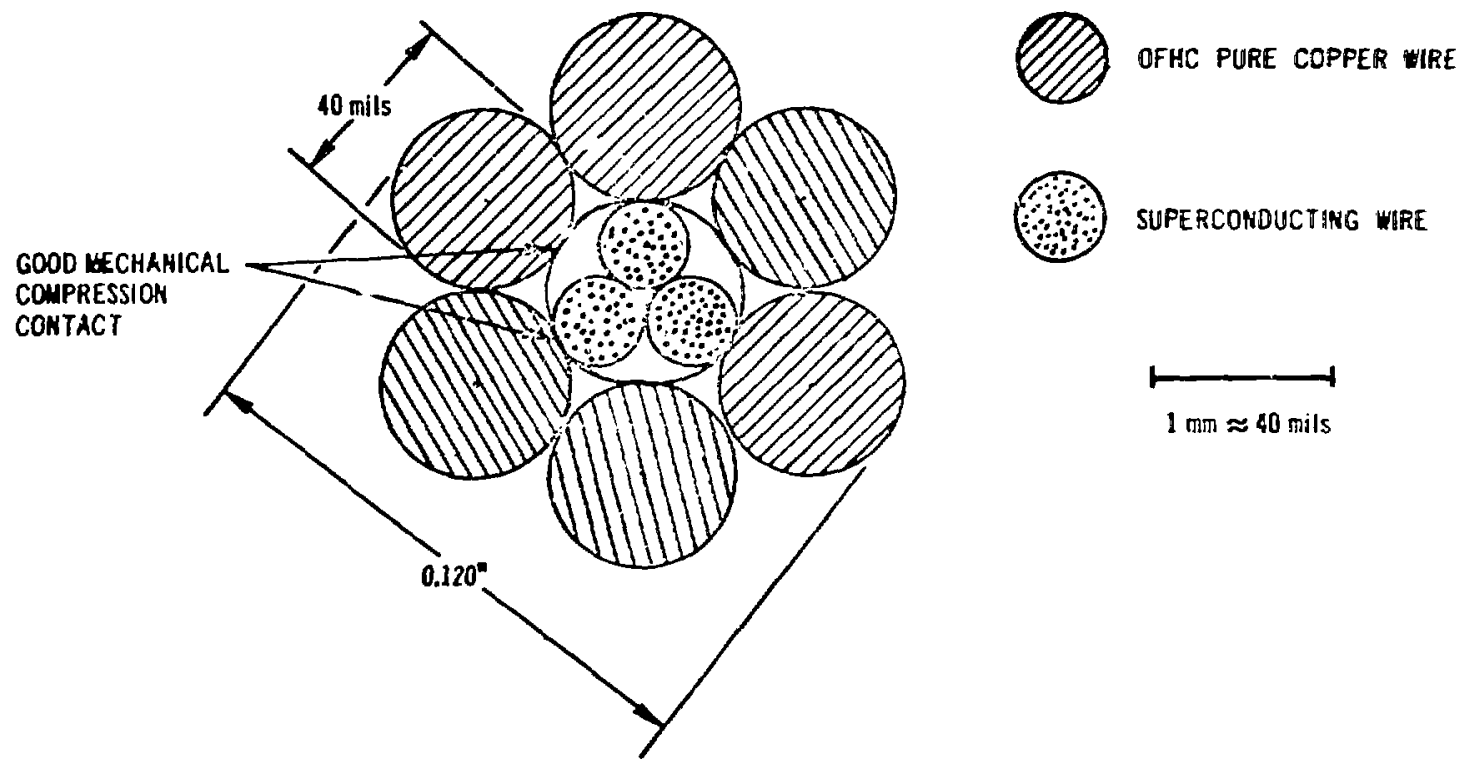

(a)

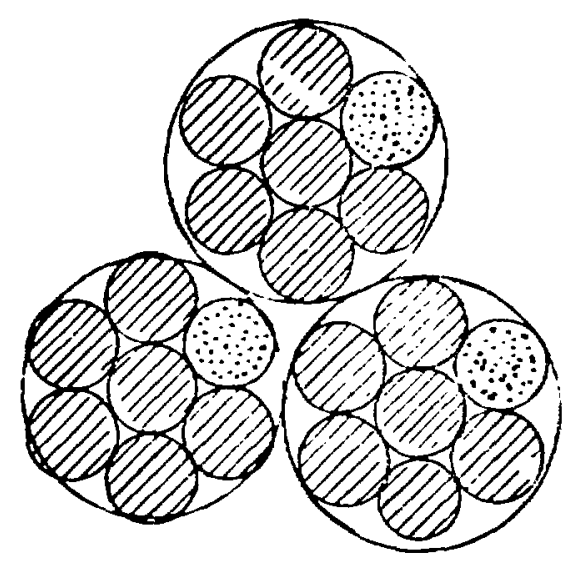

(b)

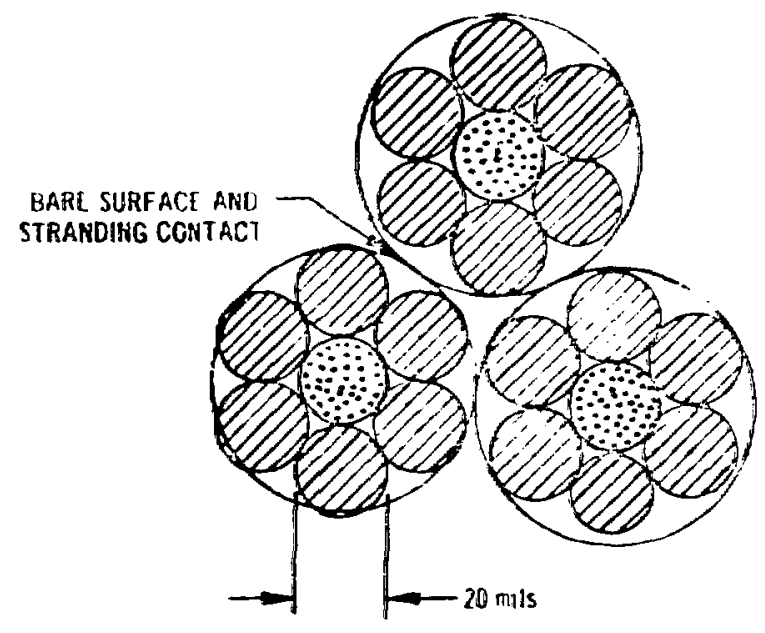

(c) 


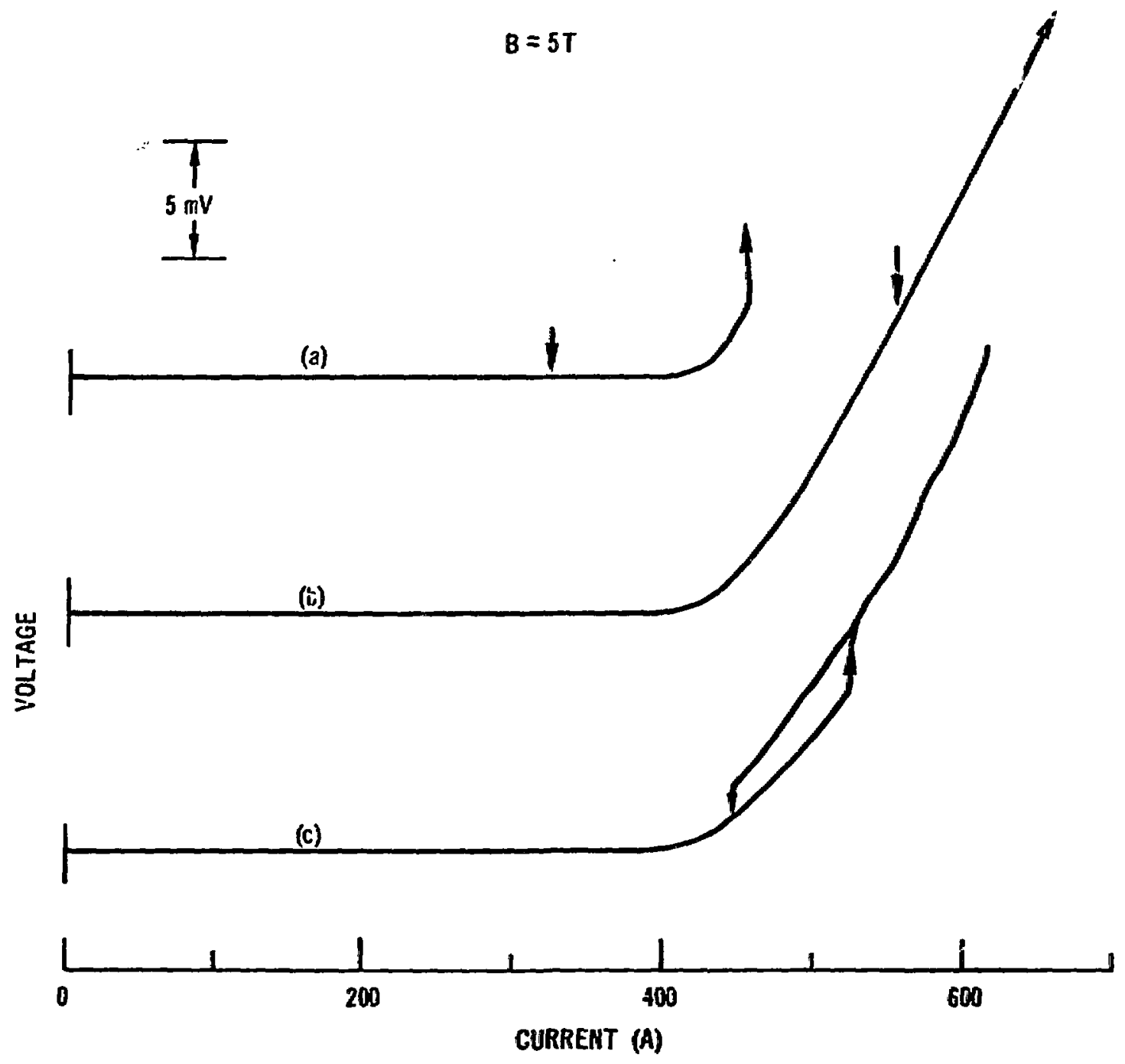



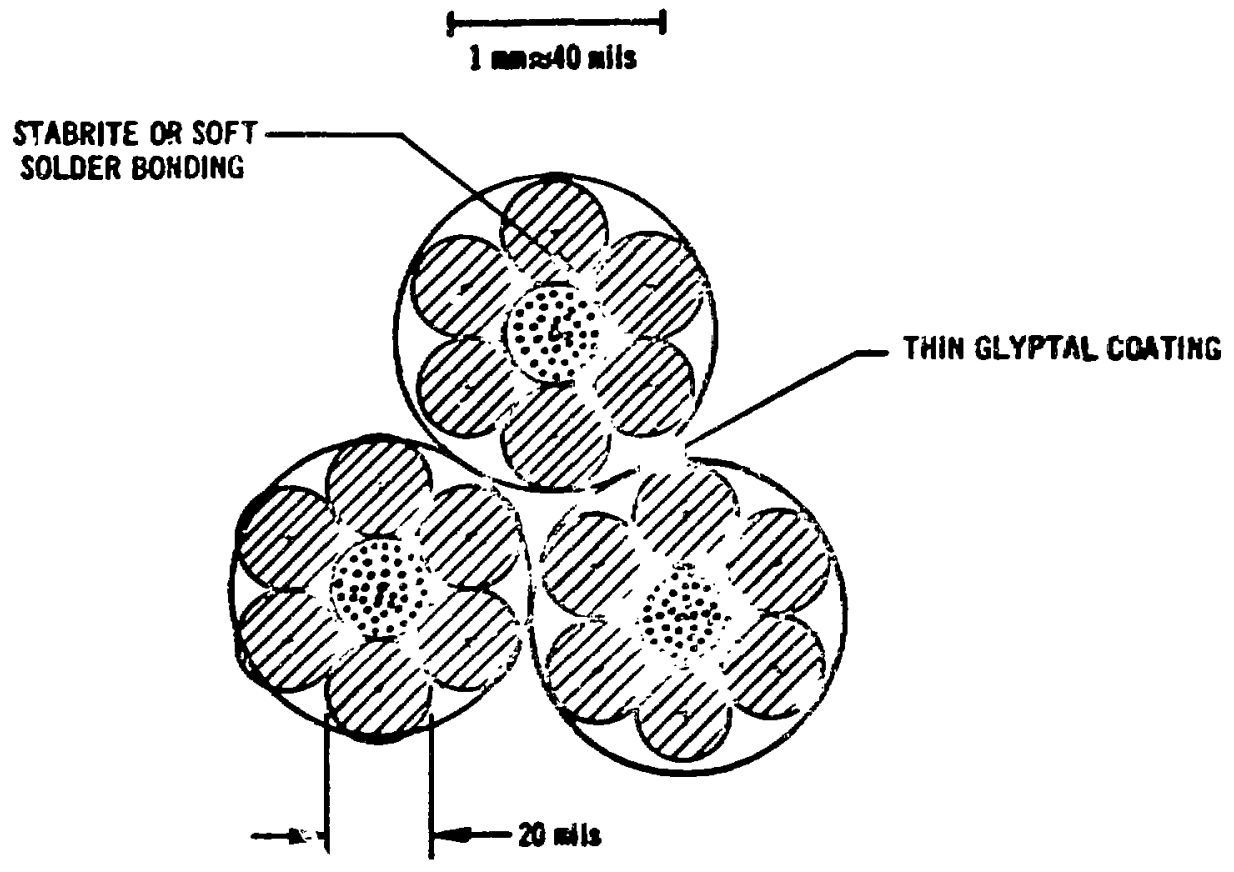

(0)

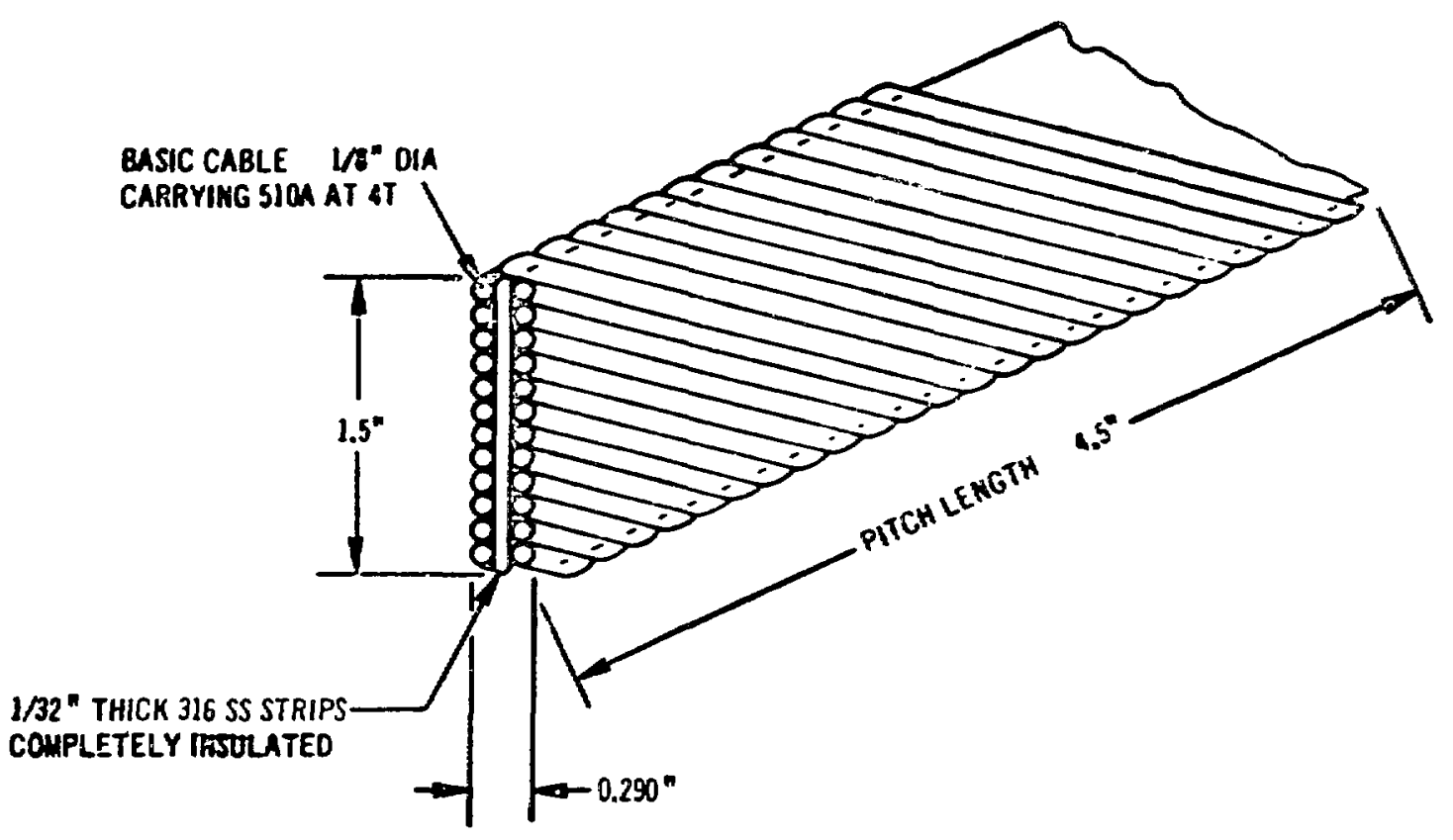




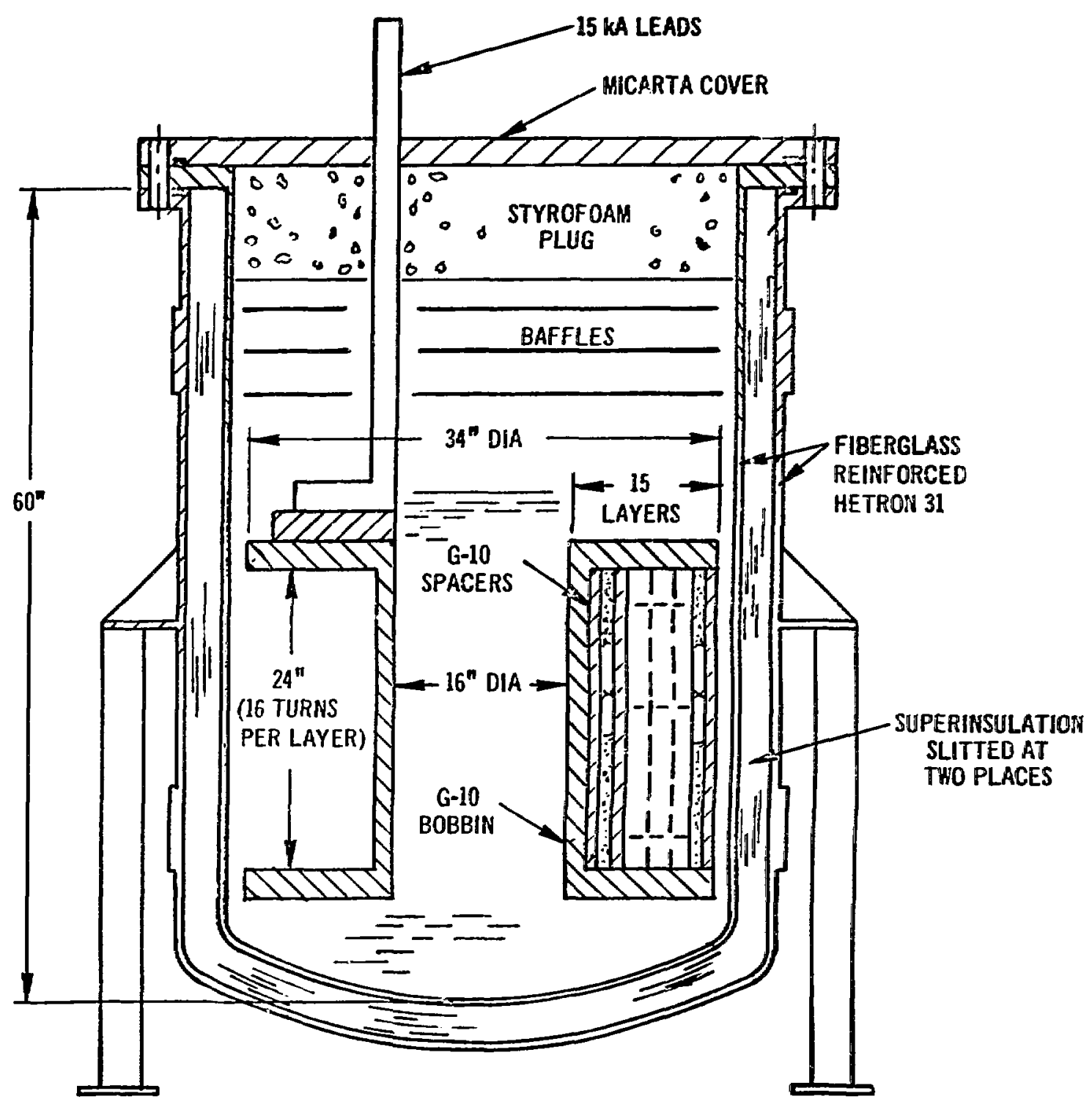

